\title{
The Further Understanding in Multimedia Teaching of College Based on Education Dissemination
}

\author{
Gao Ziqing \\ Harbin University \\ Harbin, China \\ E-mail: gaoziqing777@163.com
}

\author{
Zhang Jinping \\ School of Economics \\ Harbin University of Commerce \\ Harbin China \\ E-mail: nemo080@126.com
}

\begin{abstract}
Theoretical foundation of multimedia teaching technology development and application reviews the advantages and limitations of multimedia teaching technology in college teaching from the perspective of education dissemination. It is beneficial to scientifically and reasonably make use of multimedia teaching technology and make appropriate choice of multimedia classroom teaching mode to improve the classroom teaching effect.
\end{abstract}

Keywords-education dissemination; multimedia teaching; teaching mode

\section{INTRODUCTION}

According to media situational theory in the 1980s put forward by the American communication scholar Meyrowitz, "teaching situation" consisting of teachers, students and the blackboard is an information system in traditional teaching mode. The teacher is the information sender, the student is the information receiver, and the blackboard is the information carrier to help teachers send information and students accept information. The blackboard writing and design by the teacher will strengthen the information sent by sound carrier to make the students accept information more effectively with the help of the combination of auditory and visual channels. The blackboard is necessary tool in the higher education teaching but its limitations also restrict the effective information transfer: on one hand, the blackboard is a single color static text and graphic mediator, so that it can only display the single level information and its attraction is limited; on the other hand, its field writing influences teaching efficiency. The multimedia teaching technology makes up for the disadvantages of the traditional teaching tools. The multimedia teaching can display the dynamic image and colorful graphics, transfer a large number of teaching information in a short time and combine the auditory and visual channels and so on. But along with the application of the multimedia teaching some problems are also exposed. If all these problems can not be realized and can not be solved in time, the advantages of the multimedia teaching technology may be weakened. This article mainly analyzes the advantages and disadvantages of multimedia teaching from the perspective of education dissemination, in order to make college teachers and teaching management have a scientific cognition of multimedia teaching technology and use multimedia teaching technology appropriately and reasonably, achieving the purpose of improving the teaching effect.

\section{EDUCATION DISSEMINATION AND MULTIMEDIA TEACHING TECHNOLOGY}

Education communication is the exchange of information between the educators and the educated. Therefore, the essence of education dissemination research is to achieve effective interaction of the education information. Based on education dissemination, educational psychology, behavioral science and system science, educational technology is a subject that makes research on optimization means, operation methods in the course of education teaching process and management process. From the angel of information theory, teaching is also a kind of information dissemination activity. As the theoretical basis of modern education techniques, education dissemination is a subject that researches the disciplines of the information transmission in the course of education; And modern education techniques belongs to applied science, which studies the means which apply the theory and the system of methods from the methodology level, according to the law of human learning and information transmission, combined with human and material resources.

At present, multimedia teaching technology is an important research field of modern education techniques. Education dissemination and modern education techniques are closely related with each other. Theoretical foundation of multimedia teaching technology development and application reviews the advantages and limitations of multimedia teaching technology in college teaching from the perspective of education dissemination. It is beneficial to scientifically and reasonably make use of multimedia teaching technology.

\section{AdVAntages of Multimedia TEACHING FROM the PERSPECTIVE OF EDUCATION DISSEMINATION}

The multimedia teaching not only adds to interest and efficiency of the classroom teaching, making up for the slow information transmission speed and the lack of effect of the traditional teaching mode but also provides a very good operating platform to develop quality education reform. 


\section{A. Enhance the effect of teaching information transfer}

Both the blackboard and multimedia courseware are media that make teachers transmit teaching information and the student obtain the teaching information. Through the blackboard the teacher can only deliver teaching information with the text and simple chart, while in multimedia teaching the teacher can transfer the information with a variety of means, integrating the dynamic image and sound, static pictures, diagrams and text, and other combining static information transmission channels, so that the students receive more rich, vivid and intuitive and attractive teaching information, to achieve better teaching effect.

\section{B. Give full play to the advantages of visual media information dissemination}

In the traditional teaching mode, the students mainly have two sources to receive teaching information through the visual channel: one is a dynamic information transmission system making up of facial expressions, body postures, body movement and position changes; the second is a static information transmission system bearing the traditional teaching tools such as the blackboard and physical samples. The multimedia teaching is a combination of dynamic and static teaching information transmission system. It enhances the information expression and reproduction force through the intuitive, real dynamic image, graceful music and voiceover's explanation to apply colours to a drawing atmosphere.

\section{Make the abstract knowledge more close to reality}

In college teaching, teachers need to explain the actual operation process. In the traditional teaching mode teachers can only show and explain professional knowledge through simple graphics and text combined with vivid language to simulate real situations, but most of the real objects can't be displayed into the classroom, and it is impossible for the teachers to show real work scene to the students. Multimedia teaching can display teaching content through the analog or capture of the real image data and use bright colours and handwriting clear diagram as well to show more complex information.

\section{Increase the teaching information and improve the teaching efficiency}

First of all, by using advanced-designed multimedia courseware the teacher can quickly demonstrate the teaching contents from various aspects. Compared with the traditional teaching mode multimedia teaching can save time, provide a great amount of teaching information and improve the teaching efficiency. Secondly, the multimedia teaching can transfer more abundant teaching information through the dynamic images and chart than through language and words, it develops teaching space and at the same time widens the student's vision.

\section{E. Stimulate the students' learning interest and reduce the learning difficulty}

It is difficult for the traditional teaching mode to provide perceivable materials, Boring text and simple language description cannot form a visual image picture in the students' mind. By providing simulation or real image materials, the multimedia teaching make the abstract knowledge concrete, hard things easy and static to dynamic, to stimulate the students' interests. It conforms to the students' cognitive laws and reduces the difficulty of learning.

\section{Limitations OF Multimedia TEACHING FROM THE PERSPECTIVE OF EDUCATION DISSEMINATION}

Multimedia teaching is a double-edged sword. Compared with the traditional teaching mode, the multimedia teaching has its own advantages and advanced nature, but its limitations multimedia can not be ignored.

\section{A. There may be the recessive loss of teaching information}

Research shows that, $80 \%$ of the information in the classroom teaching is transferred by non - language voice. Dynamic posture language such as teacher's eyes, facial expressions, gestures, etc. is more attractive than static sound language. In the multimedia teaching, the teacher should always operate computer, which virtually disperse the teachers' attention, reduce the teachers' emotional input to the classroom teaching. At the same time, in order to play multimedia courseware all the time, some teachers stand (or sit) at computer operating platform to explain the multimedia courseware content, similar to the narrator or voiceover form, between the teachers and students not only space distance expanded, but the non-auditory information brought by face- to -face communication loses.

\section{B. It may scatter the students'attention}

One of the prominent auditory and visual effects may make students attracted by these non-essential teaching information. Everything has two sides and the factors can attract the attention of students, also may disperse students' attention. In the limited time and space, students are likely to be attracted by vivid and real image data, beautiful pictures and wonderful music and they are irreluctant to quickly switch to the next teaching topic. The second is the dislocation of the visual scene distracts the attention of students. In the traditional teaching mode, the teachers transmit information through the auditory channel and teachers' body language and the blackboard transmit information through the visual channel, all of which focus on students' vision in the same picture, so the students are more likely to focus their attention on the teaching content. That is the auditory cognitive effect must depend on visual effect. Now the multimedia screen replaces the blackboard. The teacher operates the computer beyond the scope of multimedia visual pictures. The students receive auditory and visual information from different source positions and the students' attention are affected. 


\section{The teacher is marginalized in the classroom teaching}

First of all, from the aspect of information communication effect, face -to -face communication is the best way of transferring the information between the students and the teachers, and it is also the best way of letting students participate in the teaching information dissemination. Secondly, from the aspect of the information flow, the text is one-way, which cannot accept students' information feedback. And flow of information between the teachers and students is two-way, namely the teacher is not only the information sender, but also the receiver of the students' feedback information .So the teacher can make the adjustment according to the students' feedback on teaching information and solve students' problems quickly. Thirdly, from the aspect of the extent of controlling information transmission, though teachers and multimedia courseware are the information senders, the teacher is e "gatekeeper", who can determine what can be received by the students through the information transmission line according to the students' different reactions. And the extent of controlling information transmission of multimedia courseware is relatively low, the teacher can control information transmission only by choosing the correspondent teaching content when they make multimedia courseware in advance. Finally, the multimedia teaching ignores the teacher can instruct and influence the students by his/her words and deed.

\section{It may weaken the training of the students' thinking} ability and innovation ability

Learning is both a process of accumulation of wisdom, and ability training process. The latter is more important for college teaching. The teacher's knowledge inference and interpretation process in the classroom is not a simple knowledge transfer, but a complicated ability training system. First of all, students learn to think from a professional perspective by observing the process of teacher's analysis, improving students' contemplative faculties; Secondly, the students learn to look for the right ideas to solve the problem through the field observation of the teachers' thinking activity line or track. Finally, students actively participate in teachers' interpretation and analysis, training their logical thinking ability, and thinking ability represents the ability of solving problems. Multimedia teaching doesn't leave students enough thinking space due to its large information capacity and quickly switched pictures.

\section{The Choice of Multimedia Teaching Mode}

Although the multimedia teaching has its own limitations, while as a kind of advanced teaching technique and tactic, it has important realistic meaning for the teaching reform of higher education.

\section{A. Multimedia netword classroom teaching mode}

Multimedia network classroom teaching mode is characteristic of the man-machine interface and local networking (as shown in fig1). Relatively speaking, in this teaching mode, man-machine interactive features encourage the students to participate in the teaching actively.
Students provide feedback to the teacher by doing in-class exercises. But the most serious defect of this teaching mode is weakening the role of the teacher in the classroom teaching. Both the teacher and students face their own computers, so that students can only receive teachers' sound information, and lose the dynamic information transferred by teacher's body language. Information feedback on teachers' teaching effect through the in-class exercises is a kind of afterwards information feedback. The teacher can't adjust and improve teaching content in time in the process of teaching. So this mode is more suitable for technical professional course teaching such as college computer and building design which is complex, and require students participate in actively, simulation teaching of economic management professional practice courses, and the open distance education.

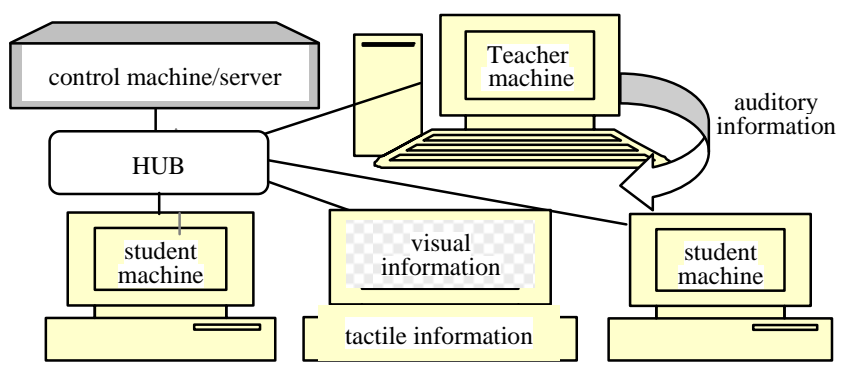

Fig 1 multimedia network classroom schematic diagram

\section{B. Multimedia audio-visual classroom teaching mode}

The multimedia audio-visual classroom teaching mode replaces the traditional platform with computer operating platform, and replaces the blackboard with multimedia big screen (as shown in fig2).

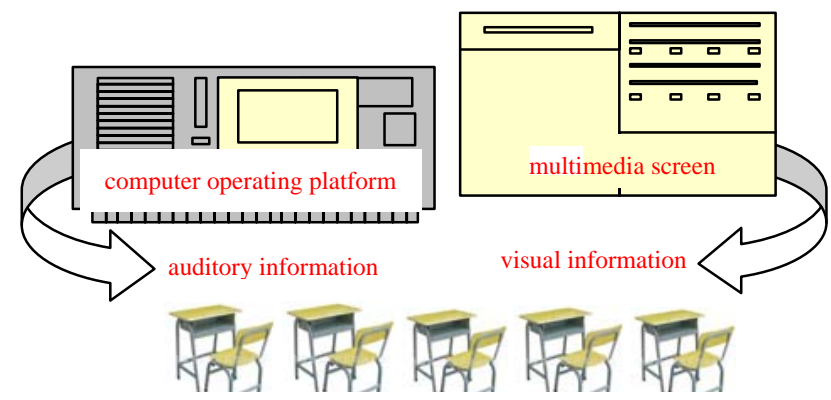

Fig 2 multimedia audio-visual classroom schematic diagram

Compared with the first mode, the hardware equipment cost of the second mode is low, but it is almost impossible for the student to participate in the teaching process, and they can only receive auditory and visual information from teachers and multimedia courseware.

Although the multimedia teaching increases the classroom teaching information because the teacher can play courseware quickly and the teacher can interpret without pause, and it provides students the static and dynamic learning platform with its intuitive, vivid image, but it didn't give students leave enough thinking space and thought forming process, and also easy to make students produce lazy psychology. In the multimedia audio-visual classroom 
teaching mode, the teachers and students' concerns are multimedia, weakening the channel function of face- to- face information transmission between the students and teacher. Therefore, the mode is generally suitable for statement conclusion type research report, and does not apply to college teaching.

\section{C. "Teacher + blackboard + multimedia" teaching mode}

"Teacher + blackboard+ multimedia" teaching mode is the organic combination of modern teaching techniques and traditional means. It retains the traditional teaching tool the blackboard and increases the advanced multimedia teaching information transmission means. Both of them together with the teacher constitute three major subjects transferring information to the student (as shown in fig3). "Teacher+ blackboard+ multimedia" teaching mode, not only regards the teaching process as the teaching information transmission system, but as a ability training system training learning and contemplative faculties, thinking ability and the correct ideas of solving the problems. In this teaching mode, multimedia courseware and the blackboard are equally important, and make full use of their advantages.

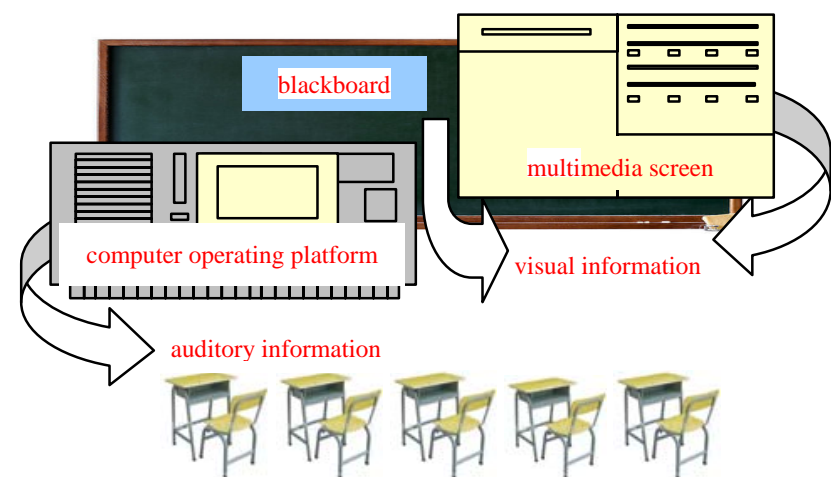

Fig 3 "teacher + blackboard + multimedia” classroom schematic diagram

In the "teacher + blackboard + multimedia" teaching mode, the blackboard and multimedia courseware are media transmitting teaching information. It is an art to realize the reasonable collocation of them. The right way is to give full play to the advantages of two kinds of teaching tools. The multimedia courseware is applied to the teaching contents that need dynamic image, and background materials, data, questions and discussion questions that need a lot of blackboard writing. The blackboard is applied to the teaching contents that need logical reasoning and chart illustration.

\section{CONCLUSION}

1)The multimedia teaching gives full play to the visual media in the information transmission, stimulating the students' interest and reduce the learning difficulty; expanding teaching information and improve the teaching efficiency and effect.

2)The multimedia teaching with real image data and elegant pictures attracts the students' attention and at the same time disperses their attention .The teachers will focus part of their attention on the play and interpretation of the multimedia courseware, resulting in the teaching information recessive loss; Students overly depend on teaching information transferred by multimedia courseware, which may make marginalization of teachers in classroom teaching. Inappropriate use of multimedia teaching technology may make students lose the opportunities of training their logical thinking ability and creative ability.

3)Teachers should choose the multimedia classroom teaching mode according to the nature of the course and teaching content.

\section{REFERENCES}

[1] Kong Xuli. Thought of multimedia teaching under modern modern education techniques[J]. China Higher Medical Education. 2008 (9) : 89-90

[2] Yang Ying. The Current Condition of Multimedia Education from the Educational Mass Eduction[J] . Journal of Longyan University. 2007 (3) : 104-107

[3] Wu Haiyan. Multimedia Teaching Environment Construction under Visual Field of Educational Ecology[J] . Modern Educational Technology. 2012 (11) : 73-76

[4] Wang Juan. Analysis on the Factor impacting the Effect of Multimedia Education and Suggestions[J] . Education Research. 2009 (5) : 95-98

[5] Liang Jin. Quality Analysis on the Multi-media Education on the basis of Higher Education[J]. Modern Distance Education. 2008 (1) : 53-55

[6] Olojo Oludare Jethro, Adewumi Moradeke Grace, Ajisola Kolawole Thomas. E-Learning and Its Effects on Teaching and Learning in a Global Age. International Journal of Academic Research in Business and Social Sciences January 2012, Vol. 2, No. 1

[7] S.Mr.Thangarajathi, Dr,T.Enok joel. Impact of Multimedia in Teaching and Learning. Golden Research Thoughts Vol.1,Issue.XI/May 2012pp.1-4

[8] Wim Westera. The eventful genesis of educational media. Education Information Technology (2012) 17:345-360 